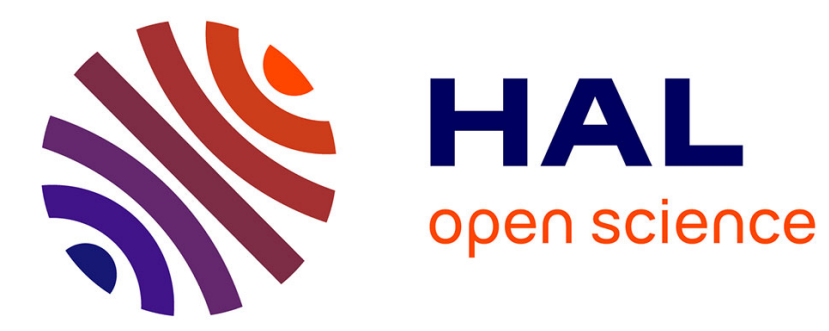

\title{
Entropy of formation of vacancies in solids
}

F. Bénière

\section{- To cite this version:}

F. Bénière. Entropy of formation of vacancies in solids. Journal de Physique Lettres, 1975, 36 (1), pp.9-12. 10.1051/jphyslet:019750036010900 . jpa-00231145

\section{HAL Id: jpa-00231145 https://hal.science/jpa-00231145}

Submitted on 1 Jan 1975

HAL is a multi-disciplinary open access archive for the deposit and dissemination of scientific research documents, whether they are published or not. The documents may come from teaching and research institutions in France or abroad, or from public or private research centers.
L'archive ouverte pluridisciplinaire HAL, est destinée au dépôt et à la diffusion de documents scientifiques de niveau recherche, publiés ou non, émanant des établissements d'enseignement et de recherche français ou étrangers, des laboratoires publics ou privés. 


\title{
ENTROPY OF FORMATION OF VACANCIES IN SOLIDS
}

\author{
F. BÉNIÈRE \\ Laboratoire d'Electrochimie $\left(^{*}\right)$, Université Paris VI \\ 9, quai Saint-Bernard, 75005 Paris, France
}

(Reçu le 5 septembre 1974)

\begin{abstract}
Résumé. - L'entropie de formation d'un défaut de Schottky, $S_{\mathrm{s}}$, est connue dans certains solides ioniques avec une précision de $10 \%$. L'entropie de fusion, $S_{\mathrm{f}}$, est également connue à $10 \%$ près. On observe la relation empirique $S_{\mathrm{s}}=3,2 S_{\mathrm{f}}$ à $20 \%$ près. Dans un calcul très simplifié on identifie les modes de vibration perturbés par la présence de la lacune à ceux de l'état liquide. On obtient en première approximation la relation $S_{\mathrm{s}}=4 S_{\mathrm{f}}$.

Abstract. - The entropy of formation of a Schottky defect, $S_{\mathrm{s}}$, is known in some ionic solids with an accuracy of $10 \%$. The entropy of fusion, $S_{\mathrm{f}}$, is also known within $10 \%$. One observes the empirical relation $S_{\mathrm{s}}=3.2 S_{\mathrm{f}}$ within $20 \%$. In a very simplified procedure, the vibration modes affected by the presence of the vacancy are identified to those in the liquid state. This leads in a first approximation to the relation $S_{\mathrm{s}}=4 S_{\mathrm{f}}$.
\end{abstract}

Among all solids, the alkali halides are particularly convenient for fundamental studies. In these crystals, the thermodynamic parameters of formation of a Schottky defect (cation vacancy + anion vacancy) can be accurately determined. This is a consequence of the strong dependence between the mole fraction of vacancies and that of impurity ions which can be added in well known amounts, for instance by using radioactive isotopes. In the last five years, the values obtained for the entropy $S_{\mathrm{s}}$ of formation of a Schottky defect in a given alkali halide agree within $\pm 10 \%$ from one laboratory to another (Table I). The reliability of these values has led us to examine in more detail the mechanism of formation of such defects.

We shall use the treatment developed by Friedel [1] whose equation accounts reasonably well for the excess entropy of transition $\mathrm{CPH}$ or $\mathrm{FCC} \rightarrow \mathrm{BCC}$ in most metals.

The entropy $S_{\mathrm{s}}$ is the difference between the entropy $S^{\prime}$ of the crystal containing one Schottky defect and the entropy $S$ of the perfect crystal. It represents the excess vibrational entropy due to a change of the lattice vibrations when the defect is created. In an ionic crystal such as $\mathrm{NaCl}, S_{\mathrm{s}}$ is the entropy of formation of a Schottky defect, i. e. of 2 vacancies. One must keep in mind this factor of 2 when comparing $S_{\mathrm{s}}$ for ionic crystals and metals, respectively.

(*) Equipe de recherche associée au CNRS ERA 310.
Let $\omega_{\mathrm{E}}$ be the Einstein frequency. We consider temperatures higher than the Einstein temperature, i. e. :

$$
T>T_{\mathrm{E}}=\hbar \omega_{\mathrm{E}} / k=h v_{\mathrm{E}} / k
$$

\section{TABLE I}

Values of the entropy of formation for a Schottky defect in alkali halides of $\mathrm{NaCl}$-structure. The experimental values are obtained from self-diffusion and conductivity data in doped crystals. The calculated values are obtained from eq. (15). Because of uncertainties in the determination of $L$, the range of error of the calculated values of $S_{\mathrm{s}}$ can be estimated to $\pm 10 \%$, $i$. e. comparable to the scatter of the experimental values of $S_{\mathrm{s}}$.

$\begin{array}{ccc}\text { Solids } & \begin{array}{c}S_{\mathrm{s}} / k \text { (calculated) } \\ \equiv 4\end{array} & \begin{array}{c}S_{\mathrm{s}} / k \text { (experimental, from } \\ \text { transport processes) }\end{array} \\ - & - & - \\ \mathrm{NaCl} & 12.6 & 9-11.5[12,13,14,15] \\ \mathrm{KCl} & 12.3 & 9-11[16,17,18,19] \\ \mathrm{KBr} & 10-12.1 & 9.6-10.3[18,20] \\ \mathrm{KI} & 11.6 & 8.3-9[15,21]\end{array}$

This is not a severe restriction, since $T_{\mathrm{E}} \sim 200-300 \mathrm{~K}$ for alkali halides, while $S_{\mathrm{s}}$ is determined from experiments carried out at

$$
T \sim 700-1100 \mathrm{~K} .
$$


For a crystal of $N$ atoms, the following expression holds within a good first order approximation [1] :

$$
S=3 k N \ln \left(k T / \hbar \omega_{\mathrm{E}}\right) .
$$

Mott and Gurney [2] assume that only the nearest neighbours of the vacancy are affected and only the vibrations along the axis joining the neighbours with the vacancy. The modes of the ions which have moved should not be affected since a new normal cell (on an average) is formed at the surface. This gives a total of 12 altered modes of pulsation $\omega_{\mathrm{E}}^{\prime}$ per Schottky pair. If one assumes that the ratio of the altered to the original frequencies is the same for cation and anion vacancies, one obtains :

$$
S_{\mathrm{s}}=S^{\prime}-S \simeq 12 k \ln \left(\omega_{\mathrm{E}} / \omega_{\mathrm{E}}^{\prime}\right) .
$$

The change in $\omega_{\mathrm{E}}$ can be due to a change in the number $p$ of bonds and to a change in the strength of the bonds [1].

Vineyard and Dienes [3] assumed that the vacancy halves the force constant. Since the vibration frequency is proportional to the square root of the force constant, eq. (2) according to Vineyard and Dienes leads to the result :

$$
S_{\mathrm{s}}=6 k \ln 2=4.16 k
$$

whereas the experimental values (Table I) are close to $10 \mathrm{k}$.

The change in the number of bonds is therefore insufficient to account for the experimental entropy of formation of vacancies in the case of the alkali halides, contrary to the case for metals [4].

It seems therefore that the relaxation, which must be important in ionic crystals, should play a role on the entropy $S_{\mathrm{s}}$ due to a change in the strength of the bonds. In the following section, a relation between $S_{\mathrm{s}}$ and the relaxation volume is derived.

Entropy of formation of vacancies and relaxation volume. - Let us consider the formation of a cation vacancy (Fig. 1). We assume that only the surrounding

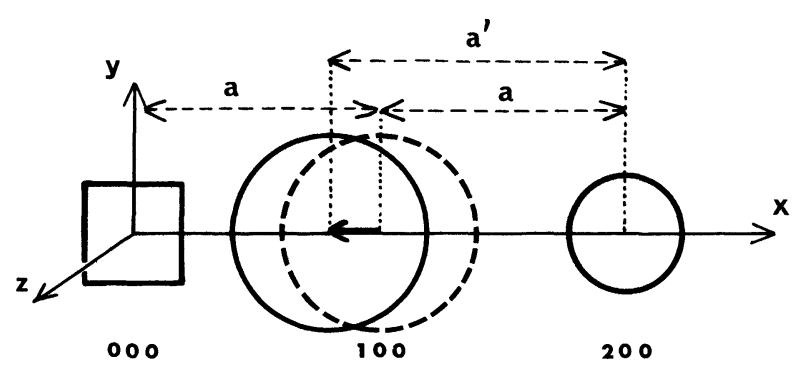

FIG. 1. - Relaxation of the nearest neighbour (100) when the vacancy $(000)$ is created.

ions of the first shell are displaced (ion 100 along the positive $x$-axis). The distance between ions 100 and 200 in the perfect crystal is the anion-cation distance $a$. Let $K$ be the force constant between ions 100 and 200 .
When the vacancy is created, the ion 100 is relaxed, the distance 100-200 becomes $a^{\prime}$ and $K$ becomes $K^{\prime}$ (the bond between 000 and 100 is suppressed as seen above, giving the contribution $\frac{1}{2} k \ln 2$ to $S_{\mathrm{s}}$ ). We may neglect in this approximate approach the second order terms due to a change in the force constant between other ion pairs. As the frequency is proportional to the square root of the force constant, the contribution to the entropy of formation of a cation vacancy due to the variation of $K$ is :

$$
3 k \ln \left(K / K^{\prime}\right)
$$

since there are 6 affected bonds around a cation vacancy in the $\mathrm{NaCl}$ lattice.

The force constant is approximately equal to the second derivative of the repulsive potential, which is properly described by the Born-Mayer potential :

$$
\varphi=C \mathrm{e}^{-r / \rho} .
$$

This gives in the cases under consideration :

$$
\begin{aligned}
& K=C \mathrm{e}^{-a / \rho} / \rho^{2} \\
& K^{\prime}=C \mathrm{e}^{-a^{\prime} / \rho} / \rho^{2} .
\end{aligned}
$$

Hence, the expression (4) takes the simple form

$$
3 k\left(a^{\prime}-a\right) / \rho \text {. }
$$

Thus, the total contribution to the formation of one cation vacancy plus one anion vacancy is given by :

$$
3 k\left(\delta a_{+}+\delta a_{-}\right) / \rho
$$

with $\delta a=a^{\prime}-a$ for each kind of vacancy.

The displacements $\delta a_{+}$and $\delta a_{-}$are clearly related to the relaxation volume $\delta V$, which is the difference between the volume of one Schottky defect and the molecular volume $V_{\mathrm{m}}$. In the $\mathrm{NaCl}$ lattice $V_{\mathrm{m}}$ is equal to :

$$
V_{\mathrm{m}}=2 a^{3}=2\left(r_{+}+r_{-}\right)^{3}
$$

where $r_{+}$and $r_{-}$are the ionic radii.

By differentiating one gets the relative relaxation volume :

$$
\frac{\delta V}{V}=3 \frac{\delta r_{+}+\delta r_{-}}{r_{+}+r_{-}}
$$

If the ion 100 is relaxed outwards by the distance $\delta r_{+}$it is clear that $a^{\prime}<a$. More precisely, we have as a result of our definitions :

$$
\delta r_{+}=-\delta a_{+} ; \quad \delta r_{-}=-\delta a_{-} .
$$

By combining (5), (7) and (8), the contribution to the entropy given by the expression (5) may be rewritten as :

$$
-\frac{a k}{\rho} \frac{\delta V}{V}
$$

where one notices that a positive relaxation volume (outwards relaxation) entails a negative contribution to $S_{\mathrm{s}}$. 
The total entropy of formation of a Schottky defect is obtained by adding the term (3) due to the change in the number of bonds and the term (9) due to the change in the strength of the bonds :

$$
\frac{S_{\mathrm{s}}}{k}=6 \ln (2)-\frac{a}{\rho} \frac{\delta V}{V} \text {. }
$$

We have calculated (Table II) the values of $S_{\mathrm{s}} / k$ derived from eq. (10) by making use of the existing relaxation volumes. The large scatter is mostly due

\section{TABLE II}

Entropy of formation of vacancies and relaxation volume. $S_{\mathrm{s}} / k$ is calculated according to eq. (10) by making use of the theoretical relaxation volumes (second column) and experimental relaxation volumes (third column).

$$
S_{\mathrm{s}} / k \quad S_{\mathrm{s}} / k
$$

Solids (theoretical $\delta V / V) \quad$ (experimental $\delta V / V)$

$\begin{array}{rrc}- & - & - \\ \mathrm{NaCl} & 10[9] & 0,-3,-6[5,6,7] \\ \mathrm{KCl} & 9[9] & -0.2[6] \\ \mathrm{KBr} & 9[9] & 3,-2.5[6,8]\end{array}$

to the controversy between experiment and theory about the relaxation volume. On one hand, the experimental relaxation volumes as inferred from the pressure dependence on the ionic conductivity by Beyeler and Lazarus [5] and Lazarus et al. [6] and on the self-diffusion coefficient by Martin et al. [7] as well as from diffuse X-ray scattering by Lohstöter et al. [8] are positive. On the other hand, the theoretical relaxation volumes calculated by Faux and Lidiard [9] are negative. It is therefore difficult to make use of these results to check the validity of the relation (10).

As an alternative suggestion, we may directly compare the ratio $\omega_{\mathrm{E}} / \omega_{\mathrm{E}}^{\prime}$ of the basic eq. (2) to the ratio $\omega_{\mathrm{S}} / \omega_{\mathrm{L}}$ of the Einstein frequencies of the atoms in the solid and liquid states $\left(\omega_{\mathrm{E}}\right.$ and $\omega_{\mathrm{S}}$ both denote the same Einstein frequency in the perfect crystal).

Entropy of formation of vacancies and entropy of fusion. - Mott [10] proposed similar expressions for the partition functions $Q_{\mathrm{S}}$ and $Q_{\mathrm{L}}$ of the solid and liquid states :

$$
\begin{aligned}
& Q_{\mathrm{S}}=\exp \left(-\frac{U_{\mathrm{S}}}{k T}\right) \frac{\exp \left(\frac{\hbar \omega_{\mathrm{S}}}{k T}\right)}{\exp \left(\frac{\hbar \omega_{\mathrm{L}}}{k T}-1\right)} 3 N \\
& Q_{\mathrm{L}}=\exp \left(-\frac{U_{\mathrm{L}}}{k T}\right) \frac{\exp \left(\frac{\hbar \omega_{\mathrm{L}}}{k T}\right)}{\exp \left(\frac{\hbar \omega_{\mathrm{L}}}{k T}-1\right)} 3 N .
\end{aligned}
$$

Mott did not take into account the contribution resulting from the exchange of atoms. In fact, as we are interested here in the formation of a vacancy inside the lattice we need not consider such a term.

$U_{\mathrm{S}}$ and $U_{\mathrm{L}}$ are the internal energies of the solid and liquid. Neglecting the small contribution due to the volume change, one has :

$$
U_{\mathrm{L}}-U_{\mathrm{S}} \simeq L
$$

the latent heat of fusion.

The condition of equilibrium of both phases at the temperature of fusion $T_{\mathrm{F}}$ gives :

$$
\left(\frac{\omega_{\mathrm{S}}}{\omega_{\mathrm{L}}}\right)^{3}=\exp \left(\frac{L}{R T_{\mathrm{F}}}\right)
$$

considering again $T_{\mathrm{F}}>T_{\mathrm{E}}$.

By combining eq. (2) and (14) one obtains :

$$
S_{\mathrm{s}}=\frac{4 k L}{R T_{\mathrm{F}}} \text {. }
$$

Eq. (15) can also be written as :

$$
S_{\mathrm{s}}=4 \frac{L}{N_{\mathrm{A}} T_{\mathrm{F}}}
$$

where $N_{\mathrm{A}}=R / k$ is Avogadro's number. By definition, the quantity $L / T_{\mathrm{F}}$ is the entropy of fusion per mole. Denoting by $S_{\mathrm{F}}$ the entropy of fusion per molecule, one gets :

$$
S_{\mathrm{s}}=4 S_{\mathrm{F}}
$$

In table I the values computed from eq. (15) are therefore equal to $4 S_{\mathrm{F}}$. Comparison of these values given by the latent heat of fusion to those experimentally obtained from transport phenomena shows the empirical relation :

$$
S_{\mathrm{s}}=3.2 S_{\mathrm{F}}
$$

within a range of error less than $20 \%$, consistent with the individual errors on $S_{\mathrm{s}}$ and $S_{\mathrm{F}}$.

We might conclude that eq. (15) is in reasonable agreement with experiment.

However, this agreement is not yet sufficient to justify our hypothesis of supposing the neighbours of the vacancy as having their vibration modes in the direction of the vacancy equal to those in the liquid state. Nevertheless, one can just notice that the volume change of fusion is positive and nearly constant and equal to $16.6-18.6 \%$ in $\mathrm{NaCl}, \mathrm{KCl}$ and $\mathrm{KBr}$ [11]. This means that the average distance between the ions in the liquid is increased relative to the solid, and hence, the force constant and pulsation should be lowered, which is in qualitative agreement with the foregoing.

Acknowledgments. - I would like to acknowledge my indebtedness to Professor J. Friedel and also to Dr. L. Dobrzynski for many stimulating discussions and helpful advices. 


\section{References}

[1] Friedel, J., J. Physique Lett. 35 (1974) L-59.

[2] Mott, N. F. and GuRney, R. W., Electronic Processes in Ionic Crystals (University Press, Oxford) 1948.

[3] Vineyard, G. H. and Dienes, G. J., Phys. Rev. 93 (1954) 265.

[4] Dobrzynski, L., J. Phys. \& Chem. Solids 30 (1969) 2395.

[5] Beyeler, M. and Lazarus, D., Solid State Commun. 7 (1969) 1487.

[6] Lazarus, D., Yoon, D. N. and Jeffery, R. N., Z. Naturforsch. 26a (1971) 56.

[7] Martin, G., Lazarus, D. and Mitchell, J. L., Phys. Rev. B 8 (1973) 1726.

[8] Lohstöter, H., Spalt, H. and Peisl, H., Phys. Rev. Lett. 29 (1972) 224.

[9] FAUX, I. D. and LidiaRd, A. B., Z. Naturforsch. 26a (1971) 62.

[10] Mott, N. F., Proc. R. Soc. 146 (1934) 465.

[11] The temperature $\left(T_{F}\right)$ and latent heat $(L)$ of fusion used in eq. (7) are the most recent values compiled in Nouveau
Traité de Chimie Minérale (Masson, Paris) 1966 and Handbook of Chemistry and Physics (52nd edition) 1972.

[12] BéNière, F., BéNière, M. and Chemla, M., J. Phys. \& Chem. Solids 31 (1970) 1205.

[13] Allnatt, A. R., Pantelis, P. and Sime, S. J., J. Phys. C : Solid State Phys. 4 (1971) 1778.

[14] Huddart, A. and Whitworth, R. W., Phil. Mag. 27 (1973) 107.

[15] Nadler, C. and Rossel, J., Phys. stat. sol. (a) 18 (1973) 711.

[16] Fuller, R. G., Marquardt, C. L., Reilly, M. H. and Wells, J. C., Phys. Rev. 176 (1968) 1036.

[17] Bénière, M., Bénière, F. and Chemla, M., J. Chim. Physique 67 (1970) 1312

[18] Chandra, S. and Rolfe, J., Can. J. Phys. 49 (1971) 2098.

[19] BÉNIÈre, M., Thesis, Paris (1974).

[20] Barr, L. W. and Dawson, D. K., Report AERE-R6234, Harwell (1969).

[21] Chandra, S. and Rolfe, J., Can. J. Phys. 48 (1970) 397. 